\title{
Comparação dos testes de virusneutralização contra os genótipos 1 e 2 do vírus da diarreia viral bovina (BVDV-1 e BVDV-2) em bovinos de rebanhos naturalmente infectados
}

\author{
Comparison of virusneutralization tests against genotypes 1 and 2 of the bovine viral diarrhoea virus \\ (BVDV-1 and BVDV-2) in cattle of naturally infected herds
}

\author{
Fabio Carvalho Dias ${ }^{I *}$ Bruna Alexandrino ${ }^{I}$ Andréa Souza Ramos de Medeiros ${ }^{\mathrm{I}}$ \\ Gener Tadeu Pereira' ${ }^{I I}$ Mônica Costa Oliveira' Samir Issa Samara ${ }^{I}$
}

RESUMO

Os resultados dos testes de virusneutralização (VN) contra os genótipos do vírus da diarreia viral bovina (BVDV-1 e BVDV-2), bem como os respectivos títulos de anticorpos, foram comparados em 1.925 amostras de soro sanguíneo obtidas de rebanhos bovinos naturalmente infectados e não vacinados contra o BVDV, provenientes dos Estados de São Paulo e Minas Gerais. A proporção de amostras reagentes entre os genótipos foi analisada pelo Teste de McNemar, e os títulos de anticorpos das amostras reagentes ao BVDV-1 e ao $B V D V-2$ foram comparados pelo Teste de Wilcoxon. Não foi verificada discordância na proporção de bovinos reagentes ao $B V D V-1$ e ao BVDV-2 (P>0,05). No entanto, houve discordância entre os títulos de anticorpos detectados nos testes de VN contra os genótipos 1 e 2 do BVDV (P<0,0001). Embora a proporção de animais reagentes contra ambos os genótipos do BVDV tenha sido semelhante, resultados falso-negativos seriam obtidos se 67 amostras (3,5\%) tivessem sido submetidas apenas ao teste de VN, para o BVDV-1, e em 51 amostras (2,65\%), apenas para o BVDV-2. Alguns rebanhos apresentaram títulos de anticorpos superiores para o BVDV-1, enquanto outros para $B V D V-2$, demonstrando assim a ocorrência da infecção pelos diferentes genótipos do vírus entre os rebanhos analisados. Portanto, tais resultados demonstraram a necessidade da inclusão de ambos os genótipos do BVDV nos testes de VN.

Palavras-chave: anticorpos neutralizantes, BVDV-1, BVDV-2, diversidade antigênica, virusneutralização.

\section{ABSTRACT}

The virusneutralization test (VN) results against bovine viral diarrhoea virus genotypes (BVDV-1 and BVDV-2), and the respective titers of antibodies, were compared in 1,925 serum samples collected from unvaccinated and naturally infected cattle herds, located in the states of São Paulo and Minas Gerais, Brazil. The proportion of reagent samples among the genotypes was evaluated by McNemar test and the antibody titers against $B V D V-1$ and $B V D V-2$ were compared by Wilcoxon test. There were no disagreement in the proportion of BVDV-1 and $B V D V-2$ reagent samples $(P>0.05)$. However, there was a disagreement among titers of antibodies detected in the VN tests against BVDV genotypes $(P<0.0001)$. Although the proportion of reagent animals to BVDV genotypes was similar, false negative results would be obtained if 67 samples (3.5\%) had been submitted only to VN test against BVDV-1, and 51 samples (2.65\%) only against BVDV-2. Some herds had higher titers of antibodies for BVDV-1, while others for BVDV-2, thus demonstrating the occurrence of infection by different virus genotypes among the analyzed herds. Therefore, these results demonstrated the need for inclusion of both BVDV genotypes in $V N$ tests.

Key words: neutralizing antibodies, $B V D V-1, B V D V-2$, antigenic diversity, virusneutralization.

\section{INTRODUÇÃO}

O vírus da diarreia viral bovina (BVDV) faz parte de um grupo distinto de vírus que causa infecções em ruminantes domésticos. Com distribuição cosmopolita, promove grandes perdas econômicas em países que se dedicam à exploração de rebanhos bovinos (GREISER-WILKE et al., 2003), apresentando uma variedade de manifestações clínicas, ressaltandose entre elas as alterações reprodutivas (HOUE, 2003). O BVDV é um RNA-vírus pertencente ao gênero

IDepartamento de Medicina Veterinária Preventiva e Reprodução Animal, Faculdade de Ciências Agrárias e Veterinárias (FCAV), Universidade Estadual Paulista (UNESP). Via de Acesso Prof. Paulo Donato Castellane, s/n, Vila Industrial, 14884-900, Jaboticabal, SP, Brasil. E-mail: fabiocadi@yahoo.com.br. *Autor para correspondência.

"Departamento de Ciências Exatas, FCAV, UNESP, Jaboticabal, SP, Brasil. 
Pestivirus e à família Flaviviridae e, por meio da análise filogenética do genoma viral, foi segregado em dois genótipos: BVDV-1 e BVDV-2 (RIDPATH et al., 1994).

Devido ao curto período de viremia que ocorre nas infecções agudas pelo BVDV, a detecção de anticorpos neutralizantes é de grande importância para o diagnóstico da enfermidade. Esses anticorpos são detectados no soro sanguíneo após três semanas do início da infecção (CHASE et al., 2003) e permanecem detectáveis pelo menos por três anos (FREDRIKSEN et al., 1999). Os anticorpos detectados pelo teste de virusneutralização (VN) são predominantemente contra a glicoproteína E2, em que estão presentes as diversidades nos determinantes antigênicos do BVDV (GOENS, 2002; BROCK, 2003; SANDVIK, 2005).

A diversidade genética do BVDV também se traduz em variabilidade antigênica. No caso dos genótipos 1 e 2 do BVDV, a diversidade existente entre eles é benéfica para a sobrevivência viral, pois favorece a evasão da resposta imune do hospedeiro (RIDPATH, 2003). Entretanto, ela interfere na realização dos testes diagnósticos e no controle da enfermidade pela vacinação (EDWARDS \& PATON, 1995; FULTON et al., 2003).

As discordâncias existentes nos resultados dos testes de VN apresentados pelos laboratórios são consequências das diferentes cepas do BVDV utilizadas (EDWARDS \& PATON, 1995; SALIKI \& DUBOVI, 2004). Além das diferentes cepas virais, outros fatores, como as linhagens celulares utilizadas, a quantidade de doses infectantes e o tempo de incubação da reação, também promovem divergências nos resultados dos testes de $\mathrm{VN}$, os quais são reflexos da falta de padronização da reação de VN entre os laboratórios (CHASE et al., 2003; KAPIL et al., 2005).

Grande parte dos laboratórios que realiza os testes de VN para o BVDV utiliza apenas cepas do BVDV-1 que, na sua maioria, são cepas de referência do vírus, as quais favorecem a leitura e interpretação dos resultados em razão da característica de alta citopatogenicidade (BROCK, 1995; EDWARDS \& PATON, 1995; SANDVICK, 2005). Entretanto, estudos já demonstraram as divergências existentes entre os resultados dos testes de VN contra o BVDV-1 e o BVDV2, bem como seus respectivos títulos de anticorpos, em bovinos vacinados ou experimentalmente infectados (FULTON et al., 1997; JONES et al., 2001; VOGEL et al., 2002; LIMA et al., 2005). Desse modo, o objetivo deste trabalho foi comparar os resultados e os títulos de anticorpos neutralizantes dos testes de VN contra o BVDV-1 e contra o BVDV-2 em bovinos de rebanhos naturalmente infectados e não vacinados contra o BVDV.

\section{MATERIAL E MÉTODOS}

\section{Amostras}

Entre os meses de janeiro de 2005 e junho de 2007, foram coletadas 1.925 amostras de sangue de bovinos não vacinados contra o BVDV, com idade superior a seis meses e provenientes de 27 rebanhos de exploração leiteira ou de corte, de variados tipos de manejo, sistemas de produção, tamanhos, raças e produtividades. Os rebanhos estavam localizados nos Municípios de Machado, Poço Fundo e São Gonçalo do Sapucaí, no Estado de Minas Gerais, e nos Municípios de Jaboticabal, Monte Alto, Sertãozinho, São Carlos, Guariba, Pedregulho, Olímpia, São José do Rio Preto, Cristais Paulista, Buritizal e Rifaina, no Estado de São Paulo. Em todos os rebanhos, foram coletadas entre 10 e 25 amostras de sangue de bovinos numa única coleta. Em quatro desses rebanhos, foram realizadas outras coletas de amostras de sangue em períodos distintos, justificando o maior número de coletas e amostras obtido nesses rebanhos. A identificação, a localização, o número de amostras e de coletas por rebanho estão demonstrados na tabela 1 .

As amostras de sangue foram coletadas em tubos siliconizados “vacutainer” $\mathrm{BD}^{\circledR} \mathrm{e}$, depois de coletadas, foram centrifugadas a $1.080 x g$. De cada amostra, foram obtidas duas alíquotas contendo $1,5 \mathrm{~mL}$ de soro sanguíneo que foram assim destinadas: uma amostra para o teste contra o BVDV-1 e outra para o teste contra o BVDV-2. As amostras foram armazenadas em freezer, a $-20^{\circ} \mathrm{C}$, até o momento do uso. A distribuição do soro sanguíneo em mais de uma alíquota foi realizada para que todas as amostras tivessem condições idênticas na manipulação antes do teste sorológico, tanto para o BVDV-1, quanto para o BVDV-2.

Teste de virusneutralização - VN

Todas as amostras foram submetidas ao teste de VN para a pesquisa de anticorpos neutralizantes contra o BVDV-1 e contra o BVDV-2(OIE, 2008). No teste de VN, foram utilizadas células epiteliais de rim bovino da linhagem Madin Darby bovine kidney (MDBK), mantidas em meio Eagle MEM (Minimal Essential Medium) Gibco $^{\circledR}$, suplementadas com $10 \%$ de soro fetal bovino (SFB) Cultilab ${ }^{\circledR}$ livre de Pestivirus e de anticorpos para o BVDV, e empregadas as cepas citopatogênicas (CP) do BVDV-1 (Singer) e do BVDV-2 (VS-253). As amostras de soro sanguíneo, antes de serem testadas, foram previamente inativadas a $56^{\circ} \mathrm{C}$, por 30 minutos. Os testes de VN foram realizados em placas de microtitulação descartáveis de 96 cavidades $\mathrm{TPP}^{\circledR}$, e o meio de manutenção Eagle-MEM Gibco ${ }^{\circledR}$, utilizado para as diluições das amostras de soro, era 
Tabela 1 - Localização dos rebanhos, número de coletas realizadas por rebanho e número total de amostras de soro sanguíneo de bovinos utilizadas na comparação dos resultados dos testes de VN para o BVDV-1 e o BVDV-2.

\begin{tabular}{|c|c|c|c|c|}
\hline Rebanho & Localização & Estado & Número de coletas & Número de amostras \\
\hline 1 & Machado & MG & 6 & 1.057 \\
\hline 2 & São Gonçalo do Sapucaí & MG & 1 & 20 \\
\hline 3 & São Gonçalo do Sapucaí & MG & 1 & 10 \\
\hline 4 & Poço Fundo & MG & 5 & 259 \\
\hline 5 & Poço Fundo & MG & 3 & 90 \\
\hline 6 & Machado & MG & 1 & 10 \\
\hline 7 & São José do Rio Preto & SP & 1 & 10 \\
\hline 8 & Jaboticabal & SP & 1 & 20 \\
\hline 9 & Sertãozinho & SP & 1 & 12 \\
\hline 10 & São Carlos & SP & 1 & 10 \\
\hline 11 & São Carlos & SP & 1 & 10 \\
\hline 12 & Jaboticabal & SP & 1 & 25 \\
\hline 13 & Jaboticabal & SP & 1 & 10 \\
\hline 14 & Guariba & SP & 1 & 28 \\
\hline 15 & Guariba & SP & 1 & 10 \\
\hline 16 & Guariba & SP & 1 & 10 \\
\hline 17 & Pedregulho & SP & 3 & 226 \\
\hline 18 & Pedregulho & SP & 1 & 10 \\
\hline 19 & Cristais Paulista & SP & 1 & 10 \\
\hline 20 & Buritizal & SP & 1 & 10 \\
\hline 21 & Pedregulho & SP & 1 & 12 \\
\hline 22 & Buritizal & SP & 1 & 10 \\
\hline 23 & Buritizal & SP & 1 & 10 \\
\hline 24 & Cristais Paulista & SP & 1 & 10 \\
\hline 25 & Monte Alto & SP & 1 & 10 \\
\hline 26 & Rifaina & SP & 1 & 10 \\
\hline 27 & Olímpia & SP & 1 & 16 \\
\hline \multicolumn{4}{|c|}{ Total de amostras coletadas } & 1.925 \\
\hline
\end{tabular}

acrescido de $1 \%$ de uma solução de penicilina (10.000UI $\mathrm{mL}^{-1}$ ) e estreptomicina (10.000ug $\mathrm{mL}^{-1}$ ) Gibco ${ }^{\circledR}$.

Para cada amostra de soro testada, foram feitas duplicatas com diluições sucessivas entre 1:10 e 1:5.120. Depois de adicionada a suspensão viral contendo $100 \mathrm{TCID}_{50}$ (50\% tissue culture infective doses) do BVDV, as microplacas foram incubadas em estufa com atmosfera de $5 \%$ de $\mathrm{CO}_{2}$ a $37^{\circ} \mathrm{C}$. Transcorridos 60 minutos, foi adicionada, em todas as cavidades das placas, uma suspensão de células MDBK contendo 300.000 células $\mathrm{mL}^{-1}$ em meio de manutenção Eagle-MEM Gibco ${ }^{\circledR}$ com $10 \%$ de SFB Cultilab $^{\circledR}$. Em seguida, a placa foi novamente incubada em estufa, a $37^{\circ} \mathrm{C}$, com atmosfera de $5 \%$ de $\mathrm{CO}_{2}$ por 96 horas. $\mathrm{Na}$ interpretação dos resultados, foram consideradas reagentes as amostras de soro sanguíneo que promoviam neutralização de 100 TCID $_{50}$ do BVDV a partir da diluição 1:10. As amostras reagentes na diluição 1:5.120 foram novamente testadas em duplicata até a diluição 1:20.480. Os títulos de anticorpos foram expressos como a recíproca da maior diluição em que foi verificada a neutralização viral, e o título final foi resultante da média geométrica dos títulos encontrados nas duplicatas.

\section{Análise estatística}

Os resultados encontrados nos testes de VN para o BVDV-1 e para o BVDV-2 foram comparados pelo Teste de McNemar, por meio de amostras pareadas em escala nominal, e com intervalo de confiança de 95\% (ZAR, 1999). A comparação dos títulos de anticorpos neutralizantes contra o BVDV-1 e contra o BVDV-2 foi realizada pelo Teste de Wilcoxon, com intervalo de confiança de 95\% (ZAR, 1999).

\section{RESULTADOS}

Teste de VN

Na tabela 2, estão sumarizados os resultados dos testes de VN para o BVDV-1 e para o BVDV-2 de todos os rebanhos analisados, assim como a média geométrica dos títulos de anticorpos encontrados nas 
Tabela 2 - Número de bovinos reagentes ao BVDV-1, reagentes ao BVDV-2 e reagentes, tanto ao BVDV-1, quanto ao BVDV-2, e médias geométricas dos títulos de anticorpos neutralizantes das amostras reagentes em 27 rebanhos localizados nos Estados de SP e MG.

\begin{tabular}{|c|c|c|c|c|c|c|c|c|}
\hline \multirow{2}{*}{ Rebanho } & \multirow{2}{*}{$\begin{array}{l}\text { Número } \\
\text { total de } \\
\text { amostras } \\
\text { testadas }\end{array}$} & \multicolumn{2}{|c|}{--------BVDV-1-------- } & \multicolumn{2}{|c|}{--------BVDV-2-------- } & \multicolumn{3}{|c|}{------------BVDV-1 e BVDV-2------------- } \\
\hline & & $\mathrm{n}^{\mathrm{a}}$ & $\begin{array}{l}\text { Média dos } \\
\text { títulos de } \\
\text { anticorpos }^{\mathrm{d}}\end{array}$ & $\mathrm{n}^{\mathrm{b}}$ & $\begin{array}{l}\text { Média dos } \\
\text { títulos de } \\
\text { anticorpos }^{\mathrm{d}}\end{array}$ & $\mathrm{n}^{\mathrm{c}}$ & $\begin{array}{l}\text { Média dos } \\
\text { títulos de } \\
\text { anticorpos } \\
\text { (BVDV-1) }^{\mathrm{d}}\end{array}$ & $\begin{array}{l}\text { Média dos } \\
\text { títulos de } \\
\text { anticorpos } \\
(\text { BVDV-2) }\end{array}$ \\
\hline 1 & 1.057 & 30 & 26 & 34 & 19 & 700 & 140 & 98 \\
\hline 2 & 20 & 0 & 0 & 1 & 80 & 12 & 90 & 143 \\
\hline 3 & 10 & 0 & 0 & 1 & 14 & 1 & 20 & 453 \\
\hline 4 & 259 & 1 & 10 & 2 & 160 & 233 & 637 & 808 \\
\hline 5 & 90 & 2 & 10 & 9 & 14 & 58 & 36 & 51 \\
\hline 6 & 10 & 0 & 0 & 0 & 0 & 4 & 269 & 95 \\
\hline 7 & 10 & 1 & 10 & 2 & 12 & 2 & 57 & 56 \\
\hline 8 & 20 & 0 & 0 & 0 & 0 & 0 & 0 & 0 \\
\hline 9 & 12 & 0 & 0 & 0 & 0 & 1 & 1280 & 320 \\
\hline 10 & 10 & 0 & 0 & 1 & 10 & 2 & 14 & 57 \\
\hline 11 & 10 & 0 & 0 & 0 & 0 & 0 & 0 & 0 \\
\hline 12 & 25 & 2 & 113 & 0 & 0 & 1 & 40 & 10 \\
\hline 13 & 10 & 0 & 0 & 0 & 0 & 2 & 14 & 14 \\
\hline 14 & 28 & 0 & 0 & 0 & 0 & 5 & 211 & 121 \\
\hline 15 & 10 & 0 & 0 & 0 & 0 & 2 & 226 & 67 \\
\hline 16 & 10 & 2 & 40 & 0 & 0 & 3 & 254 & 359 \\
\hline 17 & 226 & 11 & 12 & 12 & 12 & 143 & 88 & 44 \\
\hline 18 & 10 & 0 & 0 & 0 & 0 & 1 & 20 & 40 \\
\hline 19 & 10 & 0 & 0 & 0 & 0 & 2 & 320 & 190 \\
\hline 20 & 10 & 0 & 0 & 1 & 40 & 6 & 427 & 302 \\
\hline 21 & 12 & 1 & 10 & 0 & 0 & 6 & 180 & 50 \\
\hline 22 & 10 & 0 & 0 & 1 & 10 & 2 & 113 & 134 \\
\hline 23 & 10 & 0 & 0 & 0 & 0 & 3 & 45 & 453 \\
\hline 24 & 10 & 0 & 0 & 2 & 14 & 0 & 0 & 0 \\
\hline 25 & 10 & 0 & 0 & 0 & 0 & 4 & 57 & 34 \\
\hline 26 & 10 & 0 & 0 & 0 & 0 & 5 & 184 & 53 \\
\hline 27 & 16 & 1 & 80 & 1 & 14 & 11 & 170 & 75 \\
\hline Total (\%) & 1.925 & $\begin{array}{c}51 \\
(2,65 \%)\end{array}$ & & $\begin{array}{c}67 \\
(3,5 \%)\end{array}$ & & $\begin{array}{c}1209 \\
(62,8 \%)\end{array}$ & & \\
\hline
\end{tabular}

${ }^{\text {a }}$ Número de amostras regentes ao BVDV 1.

${ }^{\mathrm{b}}$ Número de amostras reagentes ao BVDV 2.

c Número de amostras reagentes ao BVDV 1 e ao BVDV 2.

${ }^{\mathrm{d}}$ Média geométrica dos títulos de anticorpos neutralizantes das amostras reagentes.

amostras reagentes. Do total de 1.925 amostras de soro sanguíneo, 1.209 (62,8\%) foram reagentes, tanto ao BVDV-1, quanto ao BVDV-2, 51 (2,65\%) reagiram apenas ao BVDV-1 e 67 (3,5\%) reagiram apenas ao BVDV-2. Os títulos de anticorpos neutralizantes das amostras reagentes ao BVDV-1 variaram de 10 a 20.480, e ao BVDV-2 variaram de 10 a 10.240 .

Análise estatística

Na análise realizada pelo teste de McNemar, não foi verificada discordância na proporção de bovinos reagentes ao BVDV-1 e ao BVDV-2 ( $\mathrm{P}>0,05)$. No entanto, na comparação dos títulos de anticorpos das amostras reagentes ao BVDV-1 e ao BVDV-2, realizada pelo Teste de Wilcoxon, houve discordância entre os títulos de anticorpos detectados contra os genótipos do BVDV $(\mathrm{P}<0,0001)$.

\section{DISCUSSÃO}

Embora a proporção de animais reagentes ao BVDV-1 e ao BVDV-2 tenha sido a mesma pelo Teste

Ciência Rural, v.40, n.4, abr, 2010. 
de McNemar, nos resultados dos testes de VN para o BVDV-1 e para o BVDV-2, verificou-se que, de 1.925 amostras de soro sanguíneo, 108 (6,15\%) foram reagentes apenas a um dos genótipos do BVDV. Resultados falso-negativos seriam obtidos (FLORES et al., 2000; FULTON et al., 2000; FULTON et al., 2002; CHASE et al., 2003; FLORES et al., 2005; SANDVIK, 2005) se 67 amostras (3,5\%) tivessem sido submetidas apenas ao teste de VN para o BVDV-1 e 51 amostras (2,65\%) apenas ao BVDV-2. No estudo realizado por FLORES et al. (2000), foram encontrados resultados semelhantes, com a detecção de 2,5\% de amostras reagentes somente ao BVDV-1 e 3,3\% de amostras reagentes apenas ao BVDV-2.

Na comparação dos títulos de anticorpos neutralizantes para o BVDV-1 e para o BVDV-2, realizada pelo Teste de Wilcoxon, houve discordância entre os títulos de anticorpos encontrados nas amostras reagentes aos diferentes genótipos do BVDV, demonstrando assim a variabilidade antigênica existente entre eles (EDWARDS \& PATON, 1995; BOLIN \& RIDPATH, 1996; DUBOVI, 1996; RIDPATH, 2003). Na pesquisa realizada por COUVREUR et al. (2002), sobre a variabilidade antigênica das cepas do BVDV isoladas na Bélgica, os resultados obtidos nos testes de VN também foram submetidos à análise estatística e todas as cepas pertencentes ao BVDV-1 foram imunogenicamente distintas das cepas pertencentes ao BVDV-2.

Apesar de as análises estatísticas realizadas neste estudo terem demonstrado que a proporção de animais reagentes ao BVDV-1 e ao BVDV-2 foi semelhante, a parcela de animais reagentes apenas a um dos genótipos do BVDV foi de importância epidemiológica, pois demonstrou a exposição desses animais ao vírus (FLORES, 2003). Essa observação também foi pertinente, sobretudo quando considerado o diagnóstico da infecção por rebanhos, pois, no rebanho 24 (Tabela 2), foram detectados animais reagentes apenas ao BVDV-2.

Os rebanhos que apresentaram bovinos reagentes ao BVDV poderiam estar em diferentes fases da infecção, já que os anticorpos contra o vírus podem ser detectados no soro sanguíneo 21 dias após a infecção (CHASE et al., 2003) e permanecem detectáveis pelo menos por três anos (FREDRIKSEN et al., 1999). No entanto, os títulos de anticorpos resultantes de uma infecção antiga vão declinando com o tempo (KAPIL et al., 2005), e provavelmente a baixa reatividade cruzada entre o BVDV-1 e o BVDV-2 (EDWARDS \& PATON, 1995) foi suficiente para que algumas das amostras tivessem sido reagentes apenas a um dos genótipos, tanto é que na maioria delas a média dos títulos de anticorpos foi baixa (Tabela 2).
A baixa reatividade cruzada entre o BVDV-1 e o BVDV-2 também foi demonstrada nas pesquisas realizadas por FULTON et al. (1997) e JONES et al. (2001). Nessas pesquisas, todos os bovinos apresentaram anticorpos neutralizantes contra ambos os genótipos do BVDV, porém os títulos foram bem maiores contra as cepas homólogas às cepas infectantes utilizadas nos testes de VN. Os altos títulos de anticorpos detectados, principalmente no estudo realizado por FULTON et al. (1997), podem ser justificados pela realização dos testes de VN pouco tempo após a infecção experimental dos animais analisados.

A mesma condição pôde ser verificada nesta pesquisa, especificamente nas amostras obtidas no rebanho 4, tanto com relação aos altos títulos de anticorpos detectados, como às diferenças dos títulos de anticorpos frente aos genótipos analisados. Esse foi um dos rebanhos em que foi realizada mais de uma coleta de amostra de sangue e nele também foram detectados dois animais persistentemente infectados (PI) (dados não mostrados). Em três das cinco coletas realizadas, todos os animais do rebanho que reagiram ao BVDV-1 também reagiram ao BVDV-2, mas apresentaram diferentes títulos de anticorpos nos testes de VN (dados não mostrados). Os animais desse rebanho eram mantidos num mesmo lote e provavelmente os altos títulos de anticorpos detectados eram provenientes de uma infecção recente pelo vírus ou devido ao constante estímulo imunológico do BVDV eliminado pelos animais PI.

Nas amostras que foram reagentes, tanto ao BVDV-1, quanto ao BVDV-2, as médias geométricas dos títulos de anticorpos neutralizantes contra cada genótipo apresentaram-se de forma heterogênea entre os rebanhos analisados. Em alguns deles, as médias foram semelhantes, e em outros as médias foram superiores para um determinado genótipo, apresentando também intervalos variáveis entre os títulos de anticorpos detectados para cada genótipo do BVDV (Tabela 2). Esses resultados demonstraram a variabilidade antigênica do vírus, que contribui para os diferentes resultados apresentados pelos laboratórios que realizam testes de VN para o BVDV utilizando diferentes cepas virais (EDWARDS \& PATON, 1995; CHASE et al., 2003; SALIKI \& DUBOVI, 2004; KAPIL et al., 2005).

Considerando os rebanhos que apresentaram animais reagentes com títulos de anticorpos superiores para um determinado genótipo, alguns deles apresentaram essa condição para o BVDV1 (rebanhos 6, 9, 12 e 15), enquanto outros para o BVDV2 (rebanhos 3, 4 e 23). Isso demonstra que provavelmente esses rebanhos foram infectados 
especificamente pelo BVDV-1 ou pelo BVDV-2, uma vez que os dois genótipos do BVDV já foram identificados no Brasil (BOTTON et al., 1998; FLORES et al., 2005; CORTEZ et al., 2006). Tendo em vista a diversidade antigênica do BVDV, em especial a existência de dois grupos antigênicos distintos, alguns pesquisadores enfatizaram a necessidade da utilização de cepas do BVDV-1 e do BVDV-2 nos testes de VN, pois, para uma mesma amostra de soro sanguíneo, podem ser encontrados diferentes resultados (DUBOVI, 1996; FLORES et al., 2000; CHASE et al., 2003; FULTON et al., 2003; SANDVIK, 2005).

Dessa forma, os resultados encontrados neste estudo também justificam a necessidade da inclusão do BVDV-1 e do BVDV-2 nos testes de VN realizados pelos laboratórios brasileiros. Além da utilização de ambos os genótipos do BVDV, os testes deveriam ser realizados com cepas representativas de isolados brasileiros do vírus (FLORES et al., 2000). Tais isolados apresentam uma grande variabilidade antigênica em relação a cepas norte-americanas e europeias do BVDV (BOTTON et al., 1998), dentre as quais estão incluídas as cepas tradicionalmente utilizadas pelos laboratórios que realizam os testes de VN no Brasil (BROCK, 1995; EDWARDS \& PATON, 1995; SANDVICK, 2005).

\section{CONCLUSÕES}

Uma parcela dos animais analisados apresentou anticorpos específicos somente contra um dos genótipos do BVDV, o que ocasionaria a detecção de resultados falso-negativos, caso fosse utilizado apenas um dos genótipos do vírus nos testes de VN. Houve discordância estatística entre os títulos de anticorpos apresentados pelos animais reagentes ao BVDV-1 e ao BVDV-2, comprovando assim a variabilidade antigênica existente entre os genótipos do BVDV. A detecção de animais reagentes somente ao BVDV-1 ou somente ao BVDV-2 possui importância do ponto de vista epidemiológico, enfatizando desse modo a necessidade da inclusão de cepas virais de ambos os genótipos do BVDV nos testes de VN.

\section{AGRADECIMENTOS}

Os autores agradecem ao Prof. Dr. Eduardo Furtado Flores, da Universidade Federal de Santa Maria, que gentilmente cedeu as estirpes citopatogênicas do BVDV-1 (Singer) e do BVDV2 (VS-253), para a realização das reações de VN, e à Fundação de Amparo à Pesquisa do Estado de São Paulo (FAPESP), pelo financiamento desta pesquisa.

\section{REFERÊNCIAS}

BOLIN, S.R.; RIDPATH, J.F. The clinical significance of genetic variation among bovine viral diarrhea viruses. Veterinary Medicine, Lenexa, v.91, n.10, p.958-961, 1996.

BOTTON, S. et al. Antigenic characterization of Brazilian bovine viral diarrhoea virus isolates by monoclonal antibodies and cross- neutralization. Brazilian Journal of Medical and Biological Research, Ribeirão Preto, v.31, n.11, p.14291438, 1998. Disponível em: <http://www.scielo.br/pdf/bjmbr/ v31n11/3186c.pdf>. Acesso em: 20 dez. 2009. doi: 10.1590/ S0100-879X1998001100011.

BROCK, K.V. Diagnosis of bovine viral diarrhea virus infections. Veterinary Clinics of North America: Food Animal Practice, Philadelphia, v.11, n.3, p.549-561, 1995.

BROCK, K.V. The persistence of bovine viral diarrhea virus. Biologicals, London, v.31, n.2, p.133-135, 2003. Disponível em: < http://www.sciencedirect.com/science?_ob=MI mg\& _ i m a g e k e y $=$ B $6 \mathrm{~W} \mathrm{~B} \mathrm{S-48} \mathrm{N} \mathrm{B} \mathrm{G} 4 \mathrm{~J}-$ B\&_cdi $=718 \&$ _user $=5477862 \&$ \&pii $=$ S1045105603000290\& orig = browse $\&$ _cover Date $=06 \% 2$ F $30 \% 2$ F 2003 \&_sk=999689997\&view $=c \& w c h p=d G L b V t z-$ zSkzV\&md5=8837e7d92f88a0877eaf1b0cb3cfb259\&ie=/ sdarticle.pdf $>$. Acesso 31 jan. 2010. doi:10.1016/S10451056(03)00029-0.

CHASE, C.C.L. et al. Trends in the BVDV serological response in the Upper Midwest. Biologicals, London, v.31, n.2, p.145-151, 2003. Disponível em: <http://www.sciencedirect. com/ science?_ob=MImg\&_imagekey=B6WBS-48NBG4J-D$1 \&$ _ c d i $=6718$ \&_u s e r $=5477862$ $\&_{-}$pi i $=\mathrm{S} 1045105603000320 \&$ \& orig = brow se \&_coverDate $=06 \% 2$ F $30 \% 2$ F $2003 \&$ \& sk $=99$ $9689997 \&$ vi e w $=$ c \& w c h p $=$ d G L b V t z zSkzV\&md5=e5963e973f8a318b58 dca2664fc4f7f3\&ie=/sdart icle.pdf.> Acesso em: 31 jan. 2010. doi: 10.1016/S1045-056(03)0 0032-0.

CORTEZ, A. et al. Genetic characterization of Brazilian bovine viral diarrhea virus isolates by partial nucleotide sequencing of the 5'-UTR region. Pesquisa Veterinária Brasileira, Rio de Janeiro, v.26, n.4, p.211-216, 2006. Disponível em: <http:/ /www.scielo.br/pdf/pvb/ v26n4/a05v26n4.pdf>. Acesso em: 20 nov. 2009. doi: 10.1590/S0100-736X2006000400005.

COUVREUR, B. et al. Genetic and antigenic variability in bovine viral diarrhea virus (BVDV) isolates from Belgium. Virus Research, Amsterdam, v.85, n.1, p.17-28, 2002. Disponível em: <http:// www.sciencedirect.com/science?_ob=MImg\&_imagekey=B6T32-45 519 B $4-3-9 \&_{\text {_c cdi }}=4934 \&_{\text {_us er }}=5477862 \&_{\text {_p }} \mathrm{i}$ $\mathrm{i}=\mathrm{S} 016817020200014 \mathrm{X} \&$ _orig=browse \&_cove

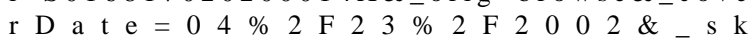
$=999149998 \&$ view $=c \& w c h p=d G L b V l z-z S k z k \& m d 5=e 5 f 2 d c$ b271013cbd9ae520b83cb1d6fe\&ie=/sdarticle.pdf $>$. Acesso em: 12 jan. 2010 .

DUBOVI, E.J. Laboratory diagnosis of bovine viral diarrhea virus infections. Veterinary Medicine, Lenexa, v.91, n.9, p.867-872, 1996.

EDWARDS, S.; PATON, D. Antigenic differences among pestiviruses. Veterinary Clinics of North America: Food Animal Practice, Philadelphia, v.11, n.3, p.563-577, 1995. 
FLORES, E.F. Vírus da diarréia viral bovina (BVDV). O Biológico, São Paulo, v.65, n.1-2, p.3-9, 2003. Disponível em: <http://www.biologico.sp.gov.br/docs/bio/v65_1_2/ flores.pdf $>$. Acesso em: 17 dez. 2009.

FLORES, E.F. et al. Diversidade antigênica de amostras do vírus da diarréia viral bovina isoladas no Brasil: implicações para o diagnóstico e estratégias de imunização. Arquivo Brasileiro de Medicina Veterinária e Zootecnia, Belo Horizonte, v.52, n.1, p.11-17, 2000. Disponível em: <http:// www.scielo.br/scielo.php?script=sci_arttext\&pid=S0102$09352000000100003 \& \operatorname{lng}=p t \& n r m=i s o>$. Acesso em $17 \mathrm{dez}$. 2009. doi: 10.1590/S0102-09352000000100 003.

FLORES, E.F. et al. A infecção pelo vírus da diarréia viral bovina (BVDV) no Brasil - histórico, situação atual e perspectivas. Pesquisa Veterinária Brasileira, Rio de Janeiro, v.25, n.3, p.125-134, 2005. Disponível em: <http:// www.scielo.br/pdf/pvb/v25n3/a02v25n3. pdf >. Acesso em: 17 dez. 2009. doi: 10.1590/S0100-736X2005000300002.

FREDRIKSEN, B. et al. Level and duration of serum antibodies in cattle infected experimentally and naturally with bovine virus diarrhoea virus. Veterinary Record, London, v.144, n.5, p.111-114, 1999.

FULTON, R. W. et al. Neutralizing antibodies to type 1 and 2 bovine viral diarrhea viruses: detection by inhibition of viral cytopathology and infectivity by immunoperoxidase assay. Clinical and Diagnostic Laboratory Immunology, Washington, v.4, n.3, p.380-383, 1997.

FULTON, R.W. et al. Bovine viral diarrhea virus cytophatic and noncytophatic biotypes and type 1 and 2 genotypes in diagnostic laboratory accessions: clinical and necropsy samples from cattle. Journal of Veterinary Diagnostic Investigation, Columbia, v.12, n.1, p.33-38, 2000. Disponível em: <http://jvdi.org/cgi/ reprint $/ 12 / 1 / 33$ ? $\mathrm{max}$ to $\mathrm{show}=\&$ HITS $=10 \&$ hits $=10 \&$ RESULTFORMAT $=1 \&$ andorexacttitle $=$ an $d \&$ andorexacttitleab $\mathrm{s}=\mathrm{a} n \mathrm{~d} \& \mathrm{a} \mathrm{nd}$ or e $\mathrm{x}$ a c t f u l l t e $\mathrm{x} \mathrm{t}=\mathrm{a}$ nd \& searchid $=1 \&$ FIRSTINDEX $=0 \&$ sortspec $=$ rele vance $\&$ volume $=12 \&$ firstpage $=33 \&$ resourcetype $=$ HWCIT $>$. Acesso em: 11 jan. 2010.

FULTON, R.W. et al. Bovine viral diarrhea virus (BVDV) 1b: predominant BVDV subtype in calves with respiratory disease. Canadian Journal of Veterinary Research, Ottawa, v.66, n.3, p.181-190, 2002. Disponível em: <http:// www.ncbi.nlm.nih.gov/pmc/articles/PMC 227002/pdf/ 20020700s00007p181.pdf >. Acesso em 03 jan. 2010.

FULTON, R. W. et al. Bovine viral diarrhoea virus antigenic diversity: impact on disease and vaccination programmes. Biologicals, London, v.31, n.2, p.89-95, 2003. Disponível em: $<\mathrm{ht} \mathrm{tp}: / / \mathrm{w} \mathrm{w}$ w. s c i e n c ed i rect. c o m/ science?_ob=MImg\&_imagekey=B6WBS-48NBG4J-2-7\&_c di $=6718 \&$ \&_user $=5477862 \&$ \& ii $=$ S 1045105603 $000216 \&$ _orig $=$ browse $\&$ _coverDate $=06 \% 2$ F 3 $0 \% 2 F 2003 \& \_s k=999689997 \& v i e w=c \& w c h p=d G L b V l z-$ zSkzS\&md5=48841cfb7a17236a4a4 b8a89a43f926e\&ie $=/$ sdarticle.pdf >. Acesso em: 11 jan. 2010. doi: 10.1016/ S10451056(03)00 021-6.

GOENS, S.D. The evolution of bovine viral diarrhea: a review. Canadian Veterinary Journal, Ottawa, v.43, n.12, p.946954, 2002. Disponível em: <http://www.ncbi.nlm.nih.gov/ pmc/
articles/PMC339916/pdf/20021200s00028p946.pdf >. Acesso em: 03 jan. 2010.

GREISER-WILKE, I. et al. Bovine viral diarrhoea eradication and control programmes in Europe. Biologicals, London, v.31, n.2, p.113-115, 2003. Disponível em: <http://www. sciencedirect.com/science?_ob=MImg\&_imagekey=B6WBS$48 \mathrm{~N} \mathrm{~B} \mathrm{G} 4 \mathrm{~J}-6-3 \&$ \& c d i $=6718$ \& 6 u s e r $=5477862 \&$ _p i i = S 10451056030002 53\&_orig=browse\&_coverDate $=06 \% 2 \mathrm{~F} \quad 30 \% 2 \mathrm{~F} 2003 \&$ _ s k = $999689997 \&$ vi e w $=c$ \& w c h p = d G L b V l z zSkzS\&md5=f7e80ca0a13bf9bb10d0437d011aee c6\&ie=/ sdarticle.pdf $>$. Acesso em: 11 jan. 2010. doi: 10.1016/S10451056(03)00025-3.

HOUE, H. Economic impact of BVDV infection in dairies. Biologicals, London, v.31, n.2, p.137-143, 2003. Disponível em: <http://www.sciencedirect.com/science?_ob=MImg\&_imag e $\mathrm{k}$ e $\mathrm{y}=\mathrm{B} 6 \mathrm{~W}$ B S $-48 \mathrm{~N}$ B G $4 \mathrm{~J}-\mathrm{C}$ 5\&_cdi $=6718 \&$ _user $=5477862 \&$ _pii $=$ S1045105603000307\&_or i g = browse $\&$ _ c over D a te $=06 \% 2$ F $30 \% 2$ F 200 $3 \&$ \& kzS \&md5 =8b 7 caa 8fdaef48a 358e 0fb 7f 1569ef02 \&ie =/ sdarticle.pdf $>$. Acesso em: 11 jan. 2010. doi: 10.1016/S10451056(03)00030-7.

JONES, L. et al. Comparison of neutralizing antibodies to type 1a, $1 \mathrm{~b}$ and 2 bovine viral diarrhea virus from experimentally infected and vaccinated cattle. Bovine Practitioner, Stillwater, v.35, n.2, p.137-140, 2001.

KAPIL, S. et al. Immunity and immunosupression. In: GOYAL, S.M.; RIDPATH, J.F. Bovine viral diarrhea virus. Iowa: Blackwell Publishing, 2005. Cap.9, p.157-170.

LIMA, M. et al. Anticorpos neutralizantes contra o vírus da Diarréia Viral Bovina (BVDV): comparação entre um imunógeno experimental atenuado e três vacinas comerciais inativadas. Ciência Rural, Santa Maria, v.35, n.1, p.230-234, 2005. Disponível em: <http://www.scielo.br/pdf/cr/v35n1/ a39v35n1.pdf>. Acesso em: 28 dez. 2009. doi: 10.1590/ S010384782005000100039.

OIE. Office International des Épizooties. Manual of standards for diagnostic tests and vaccines, Paris. Disponível em: <http://www.oie.int/eng/normes/mmanual/ A_0013_2.htm>. Acesso em: 30 ago. 2008.

RIDPATH, J. F. BVDV genotypes and biotypes: practical implications for diagnosis and control. Biologicals, London, v.31, n.2, p.127-131, 2003. Disponível em: <http://www. sciencedirect.com/science?_ob=MImg\&_imagekey=B6WBS48 N B G 4 J $-9-7 \&$ _ c d i $=6718$ \& _ u s er $=5477862 \& \_p i i=S 1045105603000289 \&$ \& orig $=$ browse $\&$ _cov erDate=06\%2F30\%2F2003\&_sk=999689997\&view=c\&wchp=dGLbVlzzSkzS\&md5=5ebaf8eee4e5b8e5ddf8e73c238a553 6\&ie=/ sdarticle.pdf $>$. Acesso em: 11 jan. 2010. doi: 10.1016/S10451056(03)00028-9.

RIDPATH, J.F. et al. Segregation of bovine viral diarrhoea virus into genotypes. Virology, New York, v.205, n.1, p.6674, 1994. Disponível em: <http://www.sciencedirect.com/ science?_ob=MImg\&_imagekey=B6WXR-45NJG71-1F-

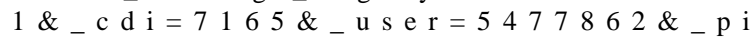
$\mathrm{i}=\mathrm{S} 0042682284716205 \&$ \& orig=browse \&_coverDate $=$ $11 \% 2$ F $15 \% 2$ F $1994 \&$ \& k $=997949998 \&$ view $=c \& w$ 
chp=dGLbVzWzSkzV\&md5=be3a3529cee6376d787ca944956a6222\&ie=/ sdarticle.pdf>. Acesso em: 28 dez. 2009.

SALIKI, J.T.; DUBOVI, E.J. Laboratory diagnosis of bovine viral diarrhea virus infections. Veterinary Clinics of North America: Food Animal Practice, Philadelphia, v.20, n.1, p.69-83, 2004.

SANDVIK, T. Selection and use of laboratory diagnostic assays in BVD control programmes. Preventive Veterinary Medicine, Amsterdam, v.72, n.1-2, p.3-16, 2005. Disponível em: <http://www.sciencedirect.com/ science?_ob=MImg\&_imagekey=B6TBK-4H 3JJ5B-118_cdi=5145\&_user=5477862\&_pii=S0167587705002102\&_ong=browse\&_cover $\mathrm{D}$ a t e $=11 \% 2 \mathrm{~F} 15 \% 2 \mathrm{~F} 2005 \%$ s k $=999$
$279998 \&$ view $=c \& w c h p=d G L z V z z-z S k W A \& m d 5=42 b b 4$ 23cd615499ab75242f944201aa2 \&ie =/sdarticle.pdf $>$. Acesso em: 28 dez. 2009 doi:10.1016/ j.prevetmed.2005.08.015.

VOGEL, F.S.F. et al. Magnitude, duração e especificidade da resposta sorológica em bovinos vacinados contra o vírus da diarréia viral bovina (BVDV). Ciência Rural, Santa Maria, v.32, n.1, p.83-89, 2002. Disponível em: <http://www.scielo.br/ pdf/cr/v32n1/a15v32n1.pdf>. Acesso em: 28 dez 2009. doi: 10.1590/S0103-84782002000100015.

ZAR, J.H. Biostatiscal analysis. 4.ed. New Jersey: Prentice Hall, 1999. 663p. 